\author{
Abd Samad, Faisal Ikram \\ Mohd Yusop, Mohd Yuzri \\ Shaharuddin, Nik Mohd Ridzuan \\ Ismail, Nasrudin \\ Yaakob, Omar Bin
}

http://dx.doi.org/10.21278/brod72104 ISSN 0007-215X

eISSN 1845-5859

\title{
SLAMMING IMPACT ACCELERATIONS ANALYSIS ON SMALL HIGH SPEED PASSENGER CRAFTS
}

UDC 629.5.017.21:629.52

Original scientific paper

\begin{abstract}
Summary
Small high speed passenger crafts (HSC) are commonly known for their poor seakeeping qualities. These crafts are frequently exposed to large slamming impacts and these repetitive shocks may pose danger to passengers' safety and health. In Malaysia, small high speed passenger crafts having lengths between 7 to 9 meters are mainly used to transport tourists between popular island destinations. Evaluation on impact and vibration for this type of craft was conducted by using accelerometers attached to several locations on craft's deck. The test was conducted at speeds ranged between 20 to 30 knots and the highest peak accelerations were recorded. The highest acceleration record during the sea trial was recorded at $4.22 \mathrm{~g}$ and the average acceleration measure is $2.20 \mathrm{~g}$. Apart from this test, evaluation on effectiveness of the current foam seat typically used in this craft were evaluated using Dynamic Response Index (DRI) and results have shown that the seat is less efficient when impact reaches more than $1 \mathrm{~g}$ at speeds of more than 20 knots. It is concluded that safety measures such as the use of more efficient suspension seat and limiting the operational speed need to be taken into consideration.
\end{abstract}

Keywords: Small high speed passenger crafts; slamming impacts; vertical accelerations Dynamics Response Index (DRI)

\section{Introduction}

One of the major concerns related to small high-speed craft is the slamming impacts. Small high-speed craft (HSC) which typically have small displacement and length are commonly known as having low seakeeping qualities. As these crafts weight is mainly carried by hydrodynamic force when moving, small high-speed craft are categorized as planing craft (Taunton et al., 2011)[1] and are exposed violently to large slamming impacts when the craft impacts the wave surface (Razola et al., 2016)[2]. These large slamming impacts resulted in large vertical accelerations of the HSC. Slamming conditions may come from small deadrise angles, shallow water and relatively high velocity between bottom hull and water surface [3]. 
When the impacts take place, the bow of the craft will rise completely out of water and subsequently impact downward on the next wave [4].

Slamming impacts towards crew and passengers not only makes them uncomfortable and possibly become seasick but may also pose danger to their safety and health. According to International Code of Safety for High-Speed Craft, for the sake of passenger safety, vertical accelerations above $1 \mathrm{~g}$ at longitudinal centre of gravity must be avoided [5]. The sudden impact of slamming experienced by HSC may reach $25 \mathrm{~g}$ in vertical accelerations [6]. This excessive impact produces vibrations which may lead to injury. The most common injuries are lower back (Jamison et al., 2013)[7] and neck fractures [8]. Several incidents have occurred towards passengers who suffered lower back wedge compression fractures as reported by Marine Accident Investigation Branch [9]. One of the incidents involved a male passenger on a Delta $8.5 \mathrm{~m}$ rigid inflatable boat (RIB) as shown in Figure 1. The accident occurred when the boat experienced wave impacts and on one occasion flung the passenger from the seat, with the passenger landed heavily on lid of a locker which was used as a seat. Data obtained on $8.5 \mathrm{~m}$ Delta RIB incidents during trials has measured that the forces acting through the deck were persistently in the region of $2 \mathrm{~g}$, with regular shocks in the range of $6 \mathrm{~g}$ and $10 \mathrm{~g}$.

The slamming impacts towards high-speed craft may also give stress to the structure and onboard systems [10]. Likewise, as these craft are very sensitive to wave disturbance, the operation of these craft are sometimes restricted. Patrol craft is limited to operate in rough water and sometimes speed has to be reduced. Craft performance such as loss of stability, propulsion inefficiency and loss of steering control are several other consequences of these impacts [11].

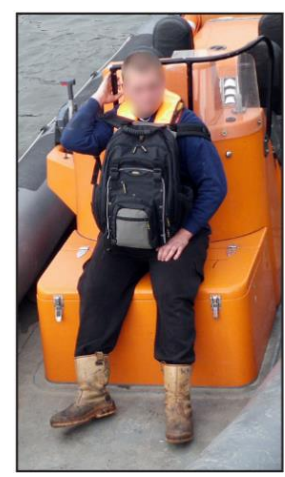

Fig. 1 The injured passenger on board Delta $8.5 \mathrm{~m}$ RIB. At the time of the accident there was only a light wind with a slight sea [9]

To overcome these dangerous impacts, several methods have been introduced ranging from various hull modifications to the use of suspension seat and suspension deck. Currently, in Malaysia, most HSC used by coastguard and navy personnel are equipped with suspension seats to mitigate the shocks. However, from the literature, such systems are less commonly used in HSCs purposely used for transporting passengers or use as a leisure craft. Less study is done to address such a problem despite the slamming impacts for these kinds of crafts also having the potential to cause harm. Practically, leisure crafts uses fixed seats and they are arranged longitudinally or transversely without suspension system and are attached directly to the deck. Thus, the key aim of this research is to investigate the severity of the slamming impact on the fixed seats for these small HSCs that are used to transport passengers or for other leisure purposes. 


\section{Slamming test with accelerometers}

To obtain real data on slamming impacts, field trial was conducted. A series of slamming tests were conducted on small passenger boat with the length of 7.9 meters that is being used as to transport tourist from Tanjung Leman Jetty, Mersing, Johor to Pulau Tinggi island. The boat particulars shown in Table 1 and Figure 2 show the overall picture of the tested boat.

Table 1 General particulars of Pulau Tinggi boat

\begin{tabular}{|l|c|}
\hline Length overall (LOA) (m) & 7.90 \\
\hline Length of waterline (LWL) (m) & 7.07 \\
\hline Breadth (m) & 2.22 \\
\hline Depth (m) & 1.13 \\
\hline LCG aft amidship (m) & 0.67 \\
\hline Displacement (tons) & 1.87 \\
\hline Full load draft (m) & 0.39 \\
\hline Deadrise angle (deg) & 25 \\
\hline Capacity of passengers & 12 \\
\hline
\end{tabular}

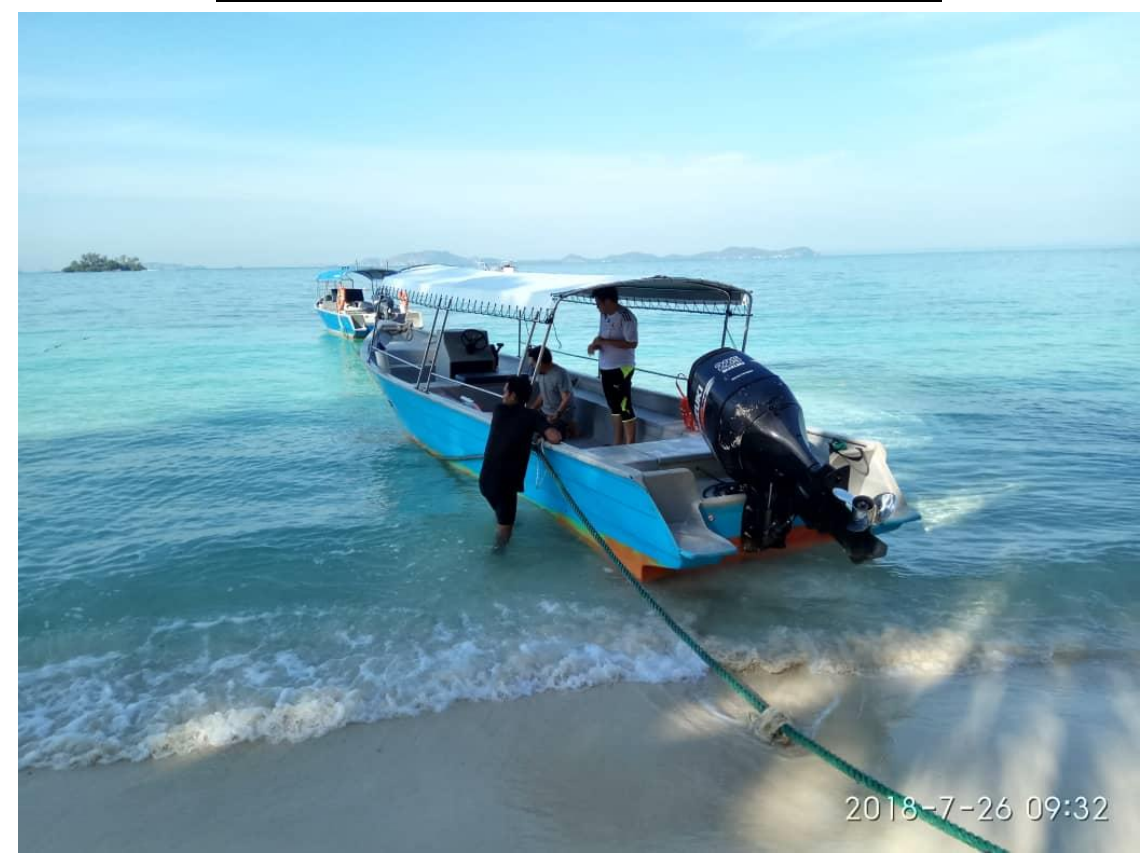

Fig. 2 Small passenger boat 7.9 meters in length

Vertical acceleration experienced by the boat was recorded and measured using accelerometers. Two accelerometers were used in this experiment, placed on several locations on boat deck to obtain deck acceleration data. The chosen locations for accelerometers are between forward bulkhead and aft bulkhead of passenger seat area, amidship section, under helmsman seat and at forward perpendicular of the boat. Accelerometers and data acquisition models and specifications are described in Section 2.2. 


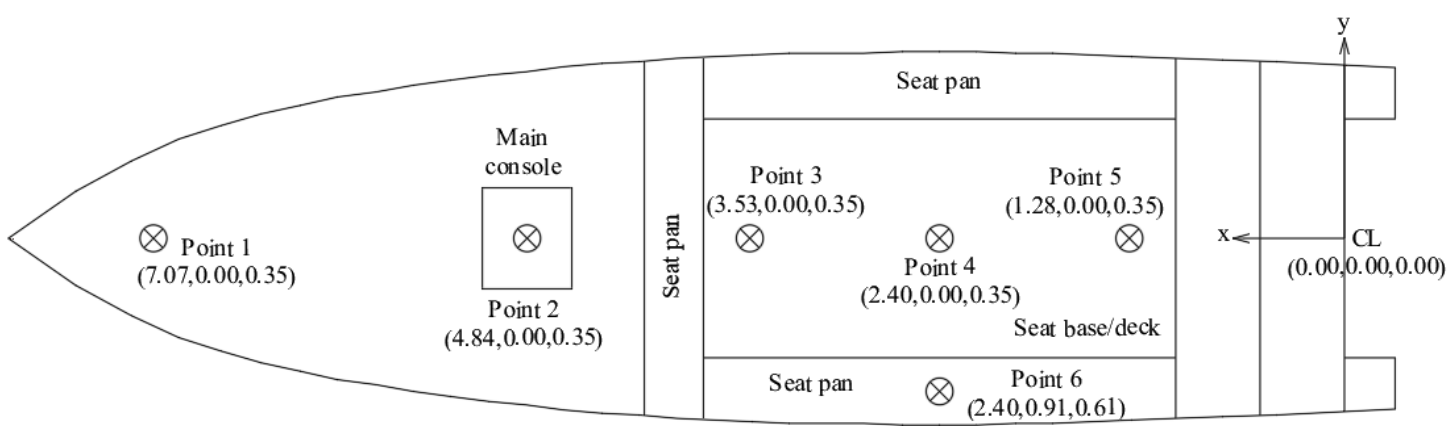

(a) Plan view and accelerometer locations

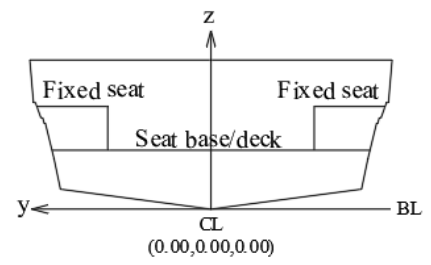

(b) Body plan view

Fig. 3 Location of accelerometer on deck and seat pan during sea test

Data was collected when the boats are using normal sailing routes. During these trials, wave characteristics were observed visually and according to wind speed measurement by using digital anemometer brand Mastech model MS6252B as shown in Figure 4(a). Figure 4(b) shows wind speed measurement for each test run. Boat speed is monitored by GPS. Figure 3 shows the locations of accelerometers and its coordinate values in $\mathrm{x}, \mathrm{y}, \mathrm{z}$ in Cartesian coordinate system. Coordinate values are in meters and are measured from stern, centreline, and baseline of the boat.

\subsection{Slamming test condition}

Speed range for the slamming test were set to be between 20 to 22 knots, 25 to 27 knots and 29 to 30 knots. The return routes from Pulau Tinggi to Tanjung Leman Jetty were chosen for the sea trial and designated Route A (from Pulau Tinggi to Tanjung Leman Jetty) and Route B (from Tanjung Leman Jetty to Pulau Tinggi). All test contained a mixture of head seas and following seas conditions.

Accelerometers were attached to desired location on thin tape to avoid damping. Figure 5 shows how accelerometers were attached on boat deck. Signal from accelerometers were checked to be received via LabVIEW user interface prior to starting the sea trials. Data signals from accelerometers was set to run and record for 120 seconds after the boat reached its test speed. The time step is 5 milliseconds, and the sampling frequency is $200 \mathrm{~Hz}$.

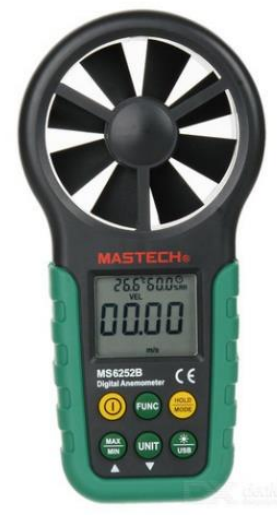

(a)

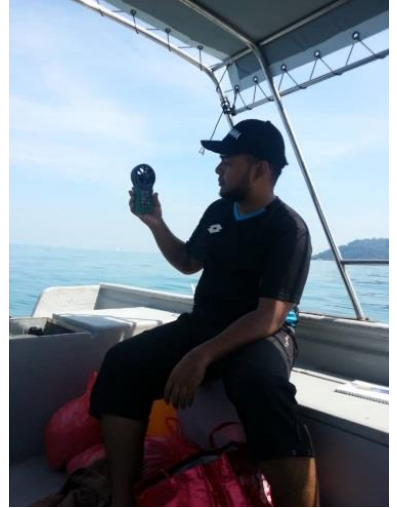

(b)

Fig. 4 Digital anemometer 


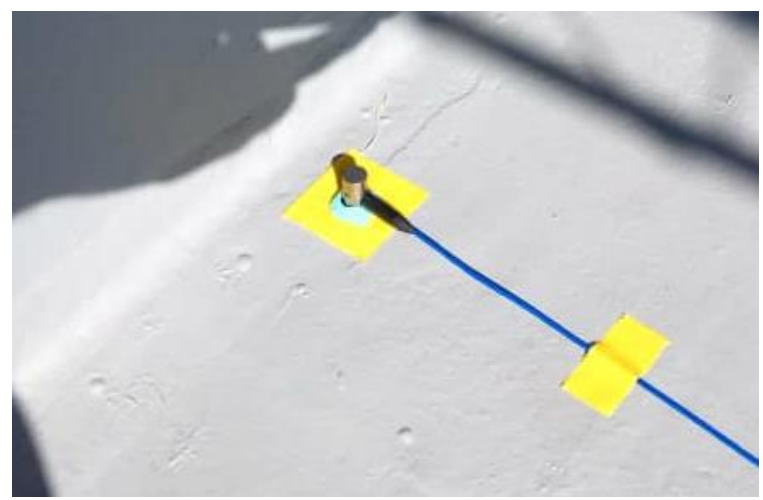

Fig. 5 Securing accelerometer on deck

\subsection{Instrumentation and measurement}

Slamming impact data were obtained by using two accelerometers, both single axis, piezoelectric accelerometers, which are also known as Integral Electronics PiezoElectric (IEPE) and with measurement range of \pm 500 g peak. Table 2 shows details on accelerometers used in these trials.

Table 2 General purpose accelerometer used in the sea trials

\begin{tabular}{|c|c|c|}
\hline Model & PCB & Kistler \\
\hline Measurement range & $\pm 500 \mathrm{~g} \mathrm{peak}$ & $\pm 500 \mathrm{~g}$ peak \\
\hline Sensitivity & $9.81 \mathrm{mV} / \mathrm{g}$ & $10 \mathrm{mV} / \mathrm{g}$ \\
\hline Frequency range & 0.5 to $10,000 \mathrm{~Hz}$ & 1 to $10,000 \mathrm{~Hz}$ \\
\hline
\end{tabular}

Data acquisition system are shown in Figure 6 which consist of controller by National Instruments model cDAQ-9174, signal conditioner for vibration and noise module by National Instruments model NI 9234 and accelerometers.

\subsection{Decomposition of rigid body motion and local deck vibrations}

The vertical acceleration recorded by accelerometers on boat deck consist of several superimposed sources of response. These consist of rigid body motions (absolute motion of the craft) which are known as heave, surge, and sway for translational motions and pitch, roll and yaw for rotational motions. The other sources of response come from local deck vibrations due to flexural response of deck due to hogging and sagging and vibration which come from the engines and propulsion system.

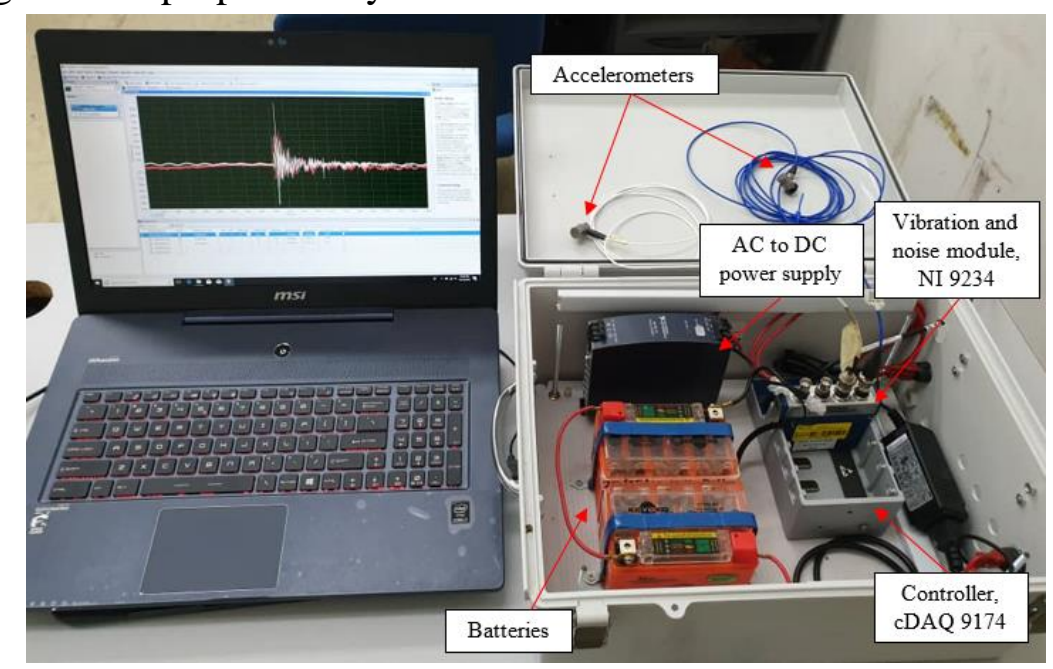

Fig. 6 Data acquisition system 
Local deck vibrations which constitute of low amplitude and high frequency characteristics mainly caused by engine and propeller vibrations have minimal effect on the slamming impact to the craft; therefore, these effects will be filtered out in the analysis.

Accelerations of rigid body motion can be assessed by applying a low-pass filter to the data acceleration records. Low-pass filter will remove high frequency content which represent local deck vibrations of the craft (Riley et al., 2013)[12]. Prior to execution of the low-pass filtering process, the cut-off frequency must be determined by using the fundamentals of Fast Fourier Transform (FFT). Fourier spectrum will be plotted to examine the suitable cut-off frequency to be used in the filtering process (Riley et al., 2014)[13], Rosén et al.,(2017)[25]. After the filtering process, the highest peak acceleration recorded in the data set will be selected as the highest slamming impact experienced by the craft.

\subsection{Seat test}

There are various models and standards available to assess human exposure to vibration and shocks in many aspects. Methods for quantifying mechanical vibration and shocks, measurements and evaluation varies according to human health conditions, comfort level, and severity of motion sickness. Some of the organizations working on the standards are International Organization for Standardization (ISO), British Standards Institute (BSI), European Committee for Standardization (CEN), Japanese Industrial Standards Committee (JISC), American National Standards Institute (ANSI), and Deutsches Institut fur Normung, Germany (DIN). Available standards are mostly based on studies carried out in relation to land based or automobile communities, thus making evaluation and assessments for vibration and shock on HSC is still in debate [14]. Vibration environments experienced by HSC are different in magnitude, exposure time and frequency. HSC crew and passengers are exposed to very high magnitude of vibration and shocks, and more transients as compared to automobile operators. However, two popular standards are adopted from other fields to evaluate the effects of HSC motion exposure to the human body and the models are Vibration Dose Value (VDV) from the automotive environment and Dynamic Response Index (DRI) from the aerospace environment. HSC communities have adopted VDV measurement to evaluate the effects of Whole-Body Vibration (WBV) (Wice, 2015 and Kirstein, 2005)[15,16] on the human body and is usually measured for a specific duration, mostly 8 hours which represents a typical workday. Equation 1 shows the formula used to evaluate the VDV of the exposed motion [14].

$$
V D V=\left[\int_{t=0}^{t=T} a^{4}(t) d t\right]^{\frac{1}{4}}
$$

VDV uses average acceleration observed and not the maximum impact value which make it unsuitable to analyze the extreme shock events experienced by the HSC passengers. Average impact acceleration is true and can be expected in the automotive environment which mostly consists of smooth roads and small undulation. As vibration occurs in many directions, VDV uses weighted root-mean-square acceleration of frequency weighted signals which provides the opportunity for uniform reporting of vibration conditions. Based on these facts, VDV are mostly used to evaluate and predict discomfort, fatigue, and the incidence of motion sickness by HSC communities.

The main objective to use suspension seats on HSC is to reduce the effect of extreme shock events hence the maximum acceleration points need to be addressed since most of the damaging impacts and source of human injuries occur at these points. For this reason, this research is focusing on evaluating the impacts by using DRI method. The determination of seat effectiveness for helmsman which is made of conventional synthetic foam is done using 
DRI. The DRI was developed by the U.S. Air Force to assess the impact of the seat ejection in aircrafts. DRI was chosen because it is calculated based on largest peak of singular event in a data set (Reynolds et al., 2012)[17]. Thus, the most severe slam impact which may cause injury to occupant's spine will be taken into consideration. By using a single degree of freedom method, DRI is modelled as human spine consisting of mass, spring and damper, which then represent maximum compression allowable of vertebral column [14]. DRI can be calculated using Equation 2 as below (U.S. Air Force. 1967)[18]:

$$
D R I=\frac{\omega_{n}^{2} \delta_{\max }}{g}
$$

where $\delta_{\max }$ is compression of the spine, $\omega_{n}^{2}$ is the square natural frequency of the spine modeled $\left(\omega_{\mathrm{n}}=52.9 \mathrm{rad} / \mathrm{s}\right)$ and $g$ is the gravity acceleration. The latter is based from previous research by [19] in which the DRI value limit is 18 , which corresponds to a $5 \%$ probability of spinal injury rates as shown in Figure 7.

Numerator of Equation 2 represents the peak or maximum acceleration of human spine and simplifies to Equation 3 as below [20]:

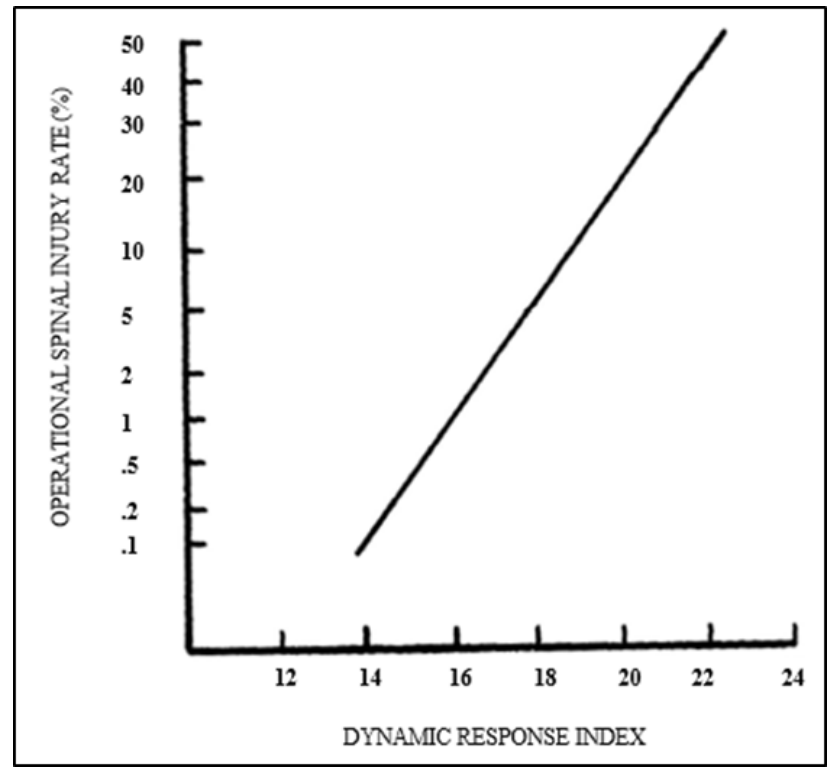

Fig. 7 Operational Spinal Injury Rate vs Dynamic Response Index (DRI)[19]

$$
D R I=\frac{\text { peak acceleration of spine }}{g}
$$

The set-up for seat effectiveness test is shown in Figure 8. Accelerometers were attached on both seat deck and seat pan. Dummy weight of $38.4 \mathrm{~kg}$ sandbags has been used to represent $72.3 \%$ of an upper body mass of a seated person to simulate a typical condition for a passenger seated on the deck seat with both feet resting on the deck [21][22].

Compression of the spine, $\delta_{\max }$ in this research represents the maximum displacement measured on the dummy weight, $d(t)$. From the fundamental of undamped steady state vibration and forced transient vibration, displacement is given by simple oscillatory motion

$$
d(t)=A \sin \omega t
$$


where $d$ is displacement at time $t$, A is maximum amplitude and $\omega$ is the frequency of oscillation. Oscillation frequency is also given by Eq. 5 where $f$ is frequency in $\mathrm{Hz}$.

$$
\omega=2 \pi f
$$

Eq. 4 then will become

$$
d(t)=A \sin 2 \pi f t
$$

Derivation of Eq. 6 will give the velocity of the vibration as

$$
v(t)=2 \pi f A \cos 2 \pi f t
$$

Derivation of Eq. 7 will give the acceleration of the vibration as

$$
a(t)=-(2 \pi f)^{2} A \sin 2 \pi f t
$$

Substitution of Eq. 6 into Eq. 8 may eliminate the time variable as

$$
a=(2 \pi f)^{2} d
$$

Minus sign is dropped for convenience. Thus, displacement $d$, is given by

$$
d=\frac{a}{(2 \pi f)^{2}}=\left(\frac{a}{4 \pi^{2}}\right)\left(\frac{1}{f^{2}}\right)
$$

\section{Results and discussion}

Experimental results are divided into two sections, slamming impact accelerations experienced by the boat during the test and the effectiveness of ordinary seat foam normally used as seat cushion on a typical boat.

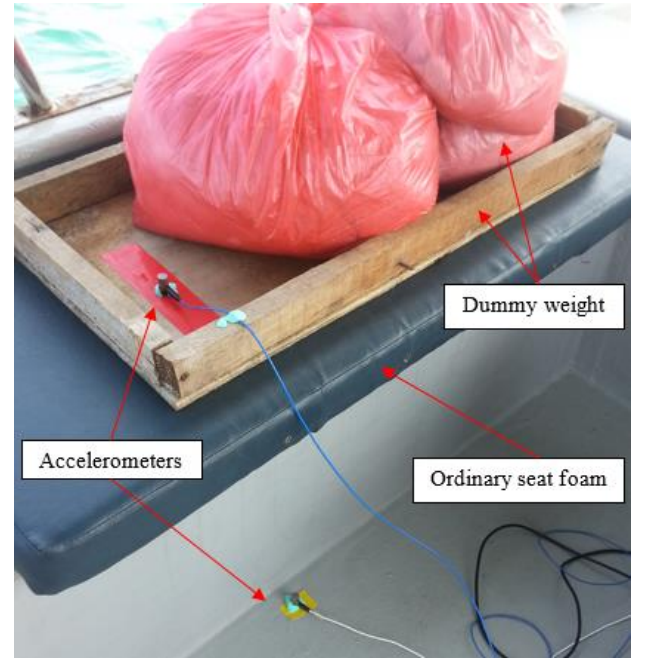

Fig. 8 Accelerometers set-up for seat effectiveness test

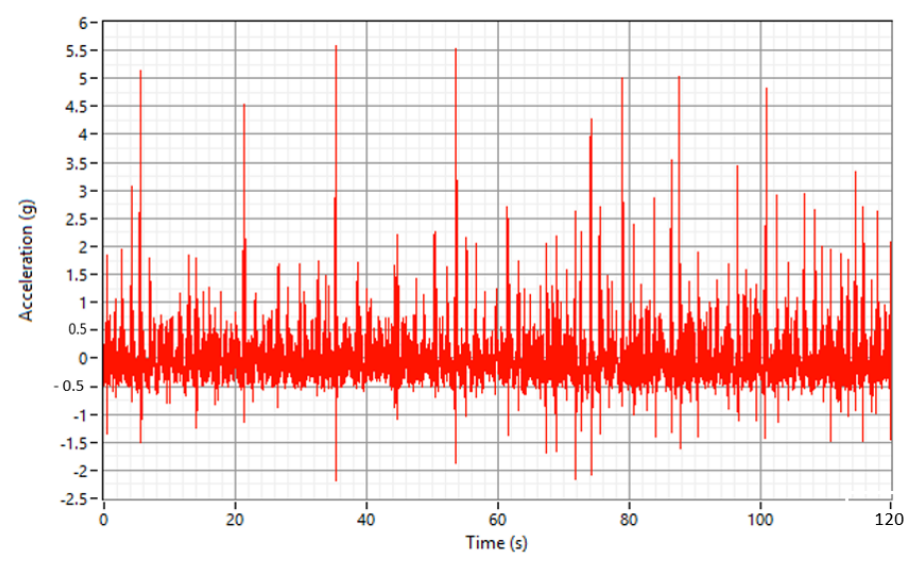

Fig. 9 Sample of unfiltered deck acceleration record by accelerometer (Test no. 3) 


\subsection{Slamming impact}

An example of unfiltered vertical deck acceleration recorded by accelerometers in time history for this experiment is shown in Figure 9. Acceleration values presented in unit $\mathrm{g}$ are the combination of rigid body motions and local deck vibrations which need to be filtered using low-pass filtering technique as mentioned earlier in Section 2.3.

Acceleration data as shown in Figure 9 then will be analyzed by using Fast Fourier Transform (FFT) to obtain a Fourier spectrum as shown in Figure 10. From Figure 10, it can be seen that the dominating acceleration amplitudes are recorded at $25 \mathrm{~Hz}$ and $33 \mathrm{~Hz}$ and some additional modes recorded at $58 \mathrm{~Hz}$. From the spectrum, the general content of acceleration amplitudes at different frequencies can be approximately categorized and used as a cut-off frequency for low-pass filtering processes.

Cut-off frequency obtained at $25 \mathrm{~Hz}$ nearly reach the recommended frequency of $10 \mathrm{~Hz}$ low-pass filtering frequency by Riley et al., (2014a)[13] for high-speed planing crafts less than $100 \mathrm{ft}$. According to Riley et al., (2014a)[13], the $10 \mathrm{~Hz}$ low-pass filtering value was only a recommendation as the exact value still depends on Fourier spectral analysis. Rosén et al.,(2017)[25] has concluded that cut-off frequency of $30 \mathrm{~Hz}$ was appropriate after comparing and combining simulated and experimental data from extensive model experiments performed at the University of Naples "Federico II" (UNINA) and simulations performed at the Royal Institute of Technology (KTH). The same cut-off frequency of $30 \mathrm{~Hz}$ also was used by Camilleri et al., (2018)[26] for assessing slamming loads on HSC 9.5m overall length in full scale. According to Camilleri et al., (2018)[26], after compared the signals at several cut-off frequencies, the $10 \mathrm{~Hz}$ cut-off frequency recommended by Riley et al., (2014a)[13] is too low hence does not signify the peak acceleration rise accurately. In the most recent study conducted by Begovic et al., (2020)[23] and Begovic et al., (2016)[24] for model experiments conducted at UNINA, the cut-off frequency of $30 \mathrm{~Hz}$ also was chosen after observing extensive measured and simulated vertical accelerations results and found to be appropriate for removing vibration content without significantly affecting the rigid body dynamics. The effects of low pass filtering at frequencies $25 \mathrm{~Hz}, 33 \mathrm{~Hz}$, and $58 \mathrm{~Hz}$ shown in Figure 11.

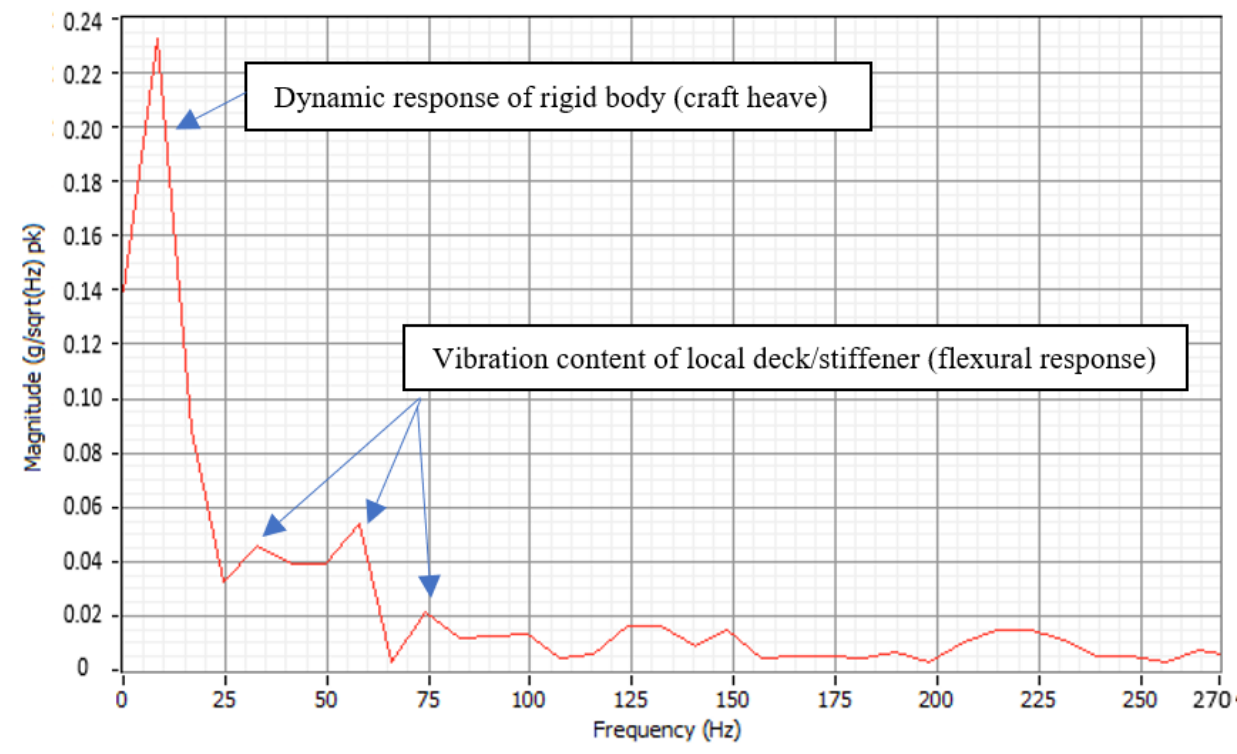

Fig. 10 Fourier spectrum of unfiltered acceleration record

From Figure 11, subset acceleration data was taken in 3 seconds time frame as to closely study the effects of low-pass filtering. It is clearly seen that the smoothness of slam records are more visible compared to unfiltered data towards $25 \mathrm{~Hz}$ filtering frequency. Figure 12 shows the superimposed graphs having these filtering frequencies. It can be 
F.I.A Samad, M.Y Mohd Yusop

N.M.R Shaharuddin, N. Ismail, O.B. Yaakob
Slamming Impact Accelerations Analysis on Small High Speed Passenger Crafts

deduced from the graph that the filtering frequency of $25 \mathrm{~Hz}$ best represents the mean value of unfiltered data signals and can be concluded to be appropriate for this study.

Slamming impact is generally known as transient vibration. However, for approximation and for the purpose of study of slamming behaviour at certain operating conditions, Figure 11(d) can give information on slamming period, peak acceleration and also the impact duration. From the figure, slamming period for two sequential events is 1.35 seconds, peak acceleration at $2.1 \mathrm{~g}$ and impact duration is $300 \mathrm{~ms}$.

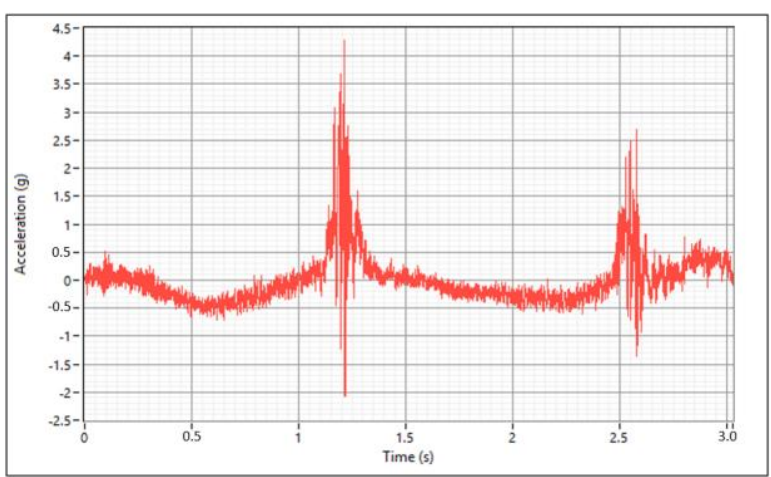

(a) Unfiltered acceleration record

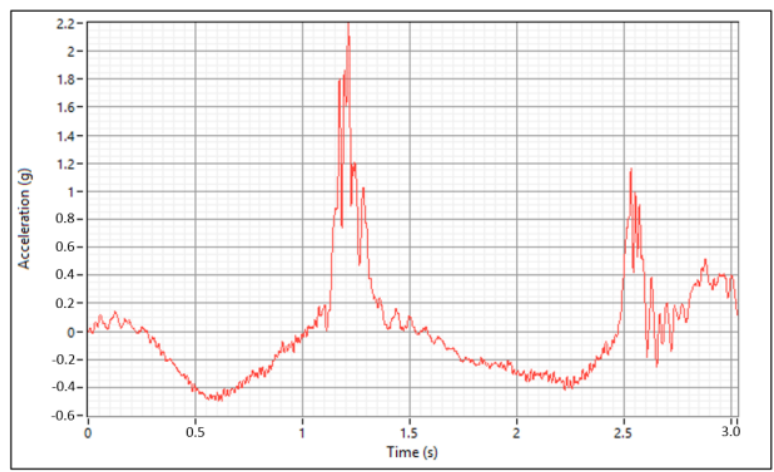

(c) Low pass filter of $33 \mathrm{~Hz}$

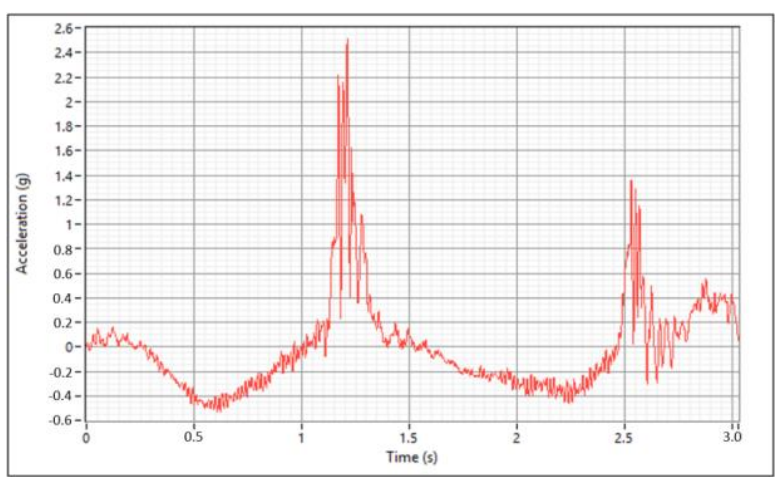

(b) Low pass filter of $58 \mathrm{~Hz}$

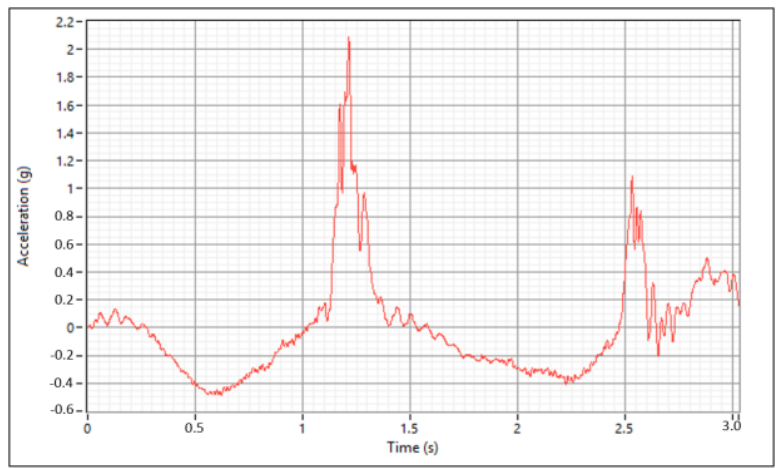

(d) Low pass filter of $25 \mathrm{~Hz}$

Fig. 11 Low pass filter (LPF) effects at different cut-off frequencies

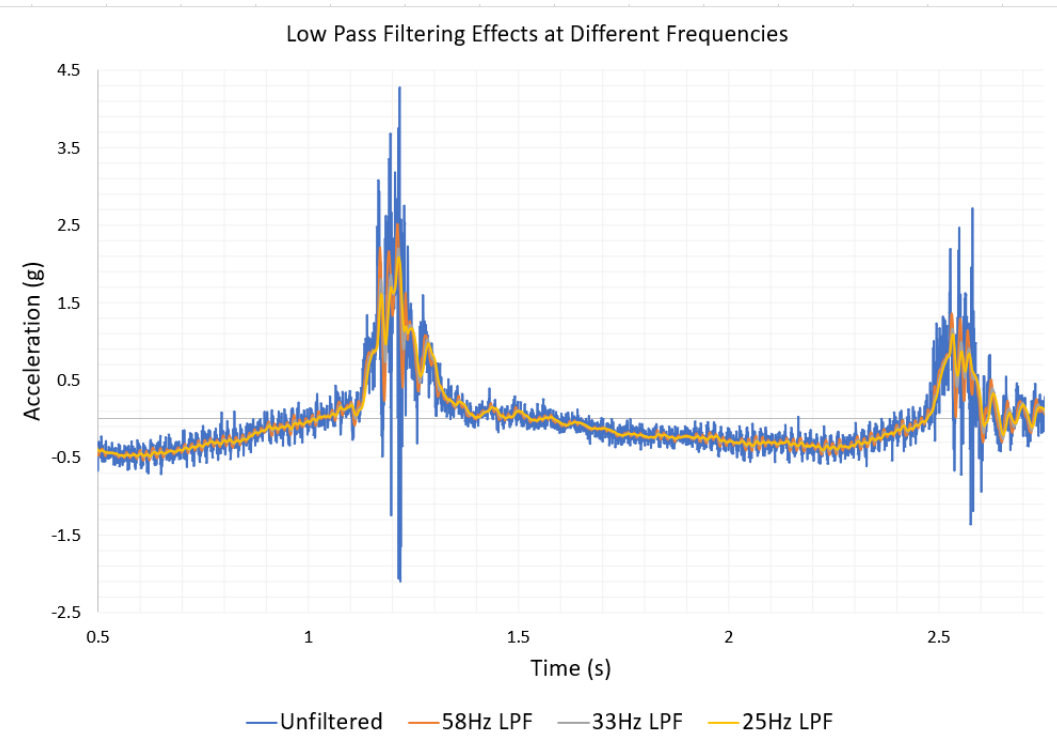

Fig. 12 Superimposed of low pass filtering effects at different frequencies towards slam impacts 
From Figure 12, peak acceleration at $2.1 \mathrm{~g}$ was originally $3.2 \mathrm{~g}$ as recorded by unfiltered wave slam data. This means that $66 \%$ of the peak acceleration records can be attributed to rigid body motion and only $34 \%$ considered to be local deck vibration content. This result correlates well with Riley et al., (2014a)[13] which obtained 64\% for rigid body motion composition. Typical wave impact duration as reported by Riley et al., (2014b)[27] is between $100 \mathrm{~ms}$ to $450 \mathrm{~ms}$. Impact duration is important for laboratory testing such as to demonstrate structure strength or testing on shock mitigation seat which are using pulse machines or freefall drop test. The laboratory test set-up needs to be developed to simulate as close as possible the real impact environments. Figure 13 shows example of slamming impact geometry for small high-speed craft conducted in this research.

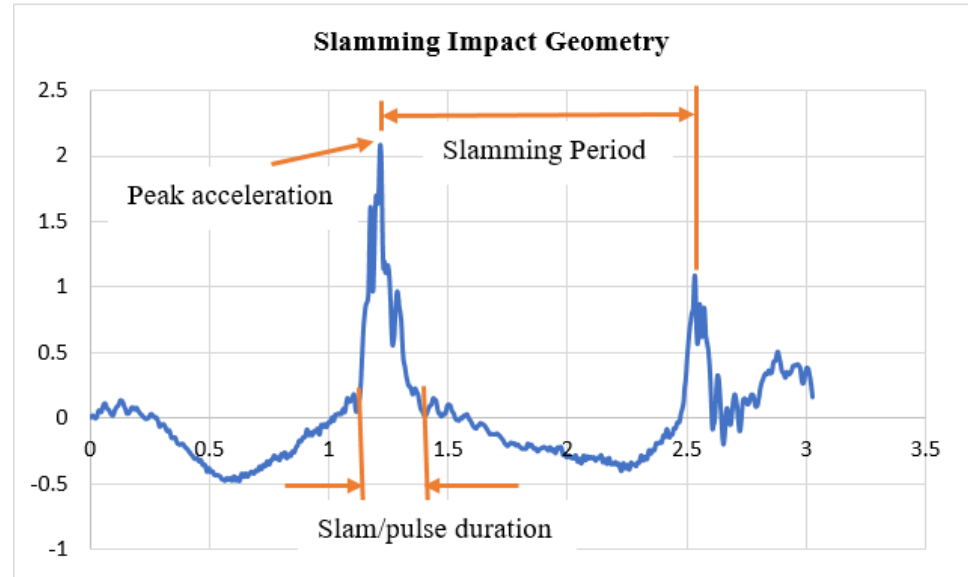

Fig. 13 Slam impacts geometry

The above results presented the value of cut-off frequency for low-pass filtering process to be applied to unfiltered data of vertical deck acceleration records obtained using accelerometers. The largest slam impact acceleration (vertical deck acceleration) in a data set at different craft speed, accelerometers locations and sea conditions obtained from slamming test after the filtering process are summarized in Table 3.

From Table 3, the highest slam impact acceleration experienced by the craft was $4.22 \mathrm{~g}$ when the accelerometer was set under the main console or at helmsman position. At the passenger seat area, the highest slam impact of $3.70 \mathrm{~g}$ was recorded at forward bulkhead with craft speed between 25 to 27 knots and the sea condition considered as calm.

Observation during the sea trial has shown that the sea conditions were between sea state 0 to sea state 2 . From the results shown in Table 3, the sea condition is not always proportionate with slam impact acceleration, for example as shown in Test no. 23 and 24 . Both were tested at same speed but Test no. 23 (sea state 1) has obtained higher value than Test no. 24 (sea state 2) where the impacts were recorded at $2.31 \mathrm{~g}$ and $2.23 \mathrm{~g}$, respectively. The average value at the forward bulkhead and main console is calculated at $2.20 \mathrm{~g}$, which is the region where the slam impacts have the greatest effect.

Tables 4, 5 and 6 show the results of acceleration record according to accelerometer location. Comparison can only be made with two locations at one time as only two accelerometers were deployed at each test run. From the table, most of the results have shown that slamming impact measured at the forward locations may give a higher value compared to the aft locations. 
F.I.A Samad, M.Y Mohd Yusop

N.M.R Shaharuddin, N. Ismail, O.B. Yaakob
Slamming Impact Accelerations Analysis on Small High Speed Passenger Crafts

Table 3 Data of slam impact acceleration for full scale sea trial (test duration of 120s per run)

\begin{tabular}{|c|c|c|c|c|c|c|c|c|c|}
\hline \multirow{2}{*}{$\begin{array}{c}\text { Test } \\
\text { no }\end{array}$} & \multicolumn{4}{|c|}{ Wind speed } & \multirow[b]{2}{*}{ Sea conditions } & \multirow{2}{*}{$\begin{array}{c}\text { Craft } \\
\text { speed } \\
\text { (knots) }\end{array}$} & \multirow{2}{*}{$\begin{array}{c}\text { Largest } \\
\text { slam impact } \\
\text { acceleration } \\
(\mathrm{g})\end{array}$} & \multirow[b]{2}{*}{$\begin{array}{c}\text { Accelerometer } \\
\text { locations }\end{array}$} & \multirow[b]{2}{*}{ Route } \\
\hline & knots & $\begin{array}{l}\text { sea } \\
\text { state }\end{array}$ & $\begin{array}{c}\text { beaufort } \\
\text { number }\end{array}$ & $\begin{array}{l}\text { wave } \\
\text { height } \\
(\mathrm{m})\end{array}$ & & & & & \\
\hline 1 & 2.66 & 0 & 1 & $0-0.2$ & Calm (glassy) & $20-22$ & 1.88 & Point 3 - FB & A \\
\hline 2 & 1.46 & 0 & 1 & $0-0.2$ & Calm (glassy) & $20-22$ & 1.9 & Point 3 - FB & B \\
\hline 3 & 0.74 & 0 & 0 & 0.00 & Calm (glassy) & $25-27$ & 3.7 & Point 3 - FB & A \\
\hline 4 & 3.19 & 0 & 1 & $0-0.2$ & Calm (glassy) & $25-27$ & 3.23 & Point 3 - FB & B \\
\hline 5 & 0.49 & 0 & 0 & 0.00 & Calm (glassy) & $29-30$ & 2.73 & Point 3 - FB & A \\
\hline 6 & 1.46 & 0 & 1 & $0-0.2$ & Calm (glassy) & $29-30$ & 2.53 & Point 3 - FB & B \\
\hline 7 & 0.25 & 0 & 0 & 0.00 & Calm (glassy) & $20-22$ & 1.29 & Point 3 - FB & A \\
\hline 8 & 1.22 & 0 & 1 & $0-0.2$ & Calm (glassy) & $20-22$ & 0.41 & Point 3 - FB & B \\
\hline 9 & 0.49 & 0 & 0 & 0.00 & Calm (glassy) & $25-27$ & 1.85 & Point 3 - FB & A \\
\hline 10 & 1.94 & 0 & 1 & $0-0.2$ & Calm (glassy) & $25-27$ & 1.29 & Point 3 - FB & B \\
\hline 11 & 0.25 & 0 & 0 & 0.00 & Calm (glassy) & $29-30$ & 2.61 & Point 3 - FB & A \\
\hline 12 & 1.46 & 0 & 1 & $0-0.2$ & Calm (glassy) & $29-30$ & 1.16 & Point 3 - FB & B \\
\hline 13 & 0.74 & 0 & 0 & 0.00 & Calm (glassy) & $20-22$ & 1.62 & Point 2 - MC & A \\
\hline 14 & 1.71 & 0 & 1 & $0-0.2$ & Calm (glassy) & $20-22$ & 0.42 & Point 2 - MC & B \\
\hline 15 & 0.25 & 0 & 0 & 0.00 & Calm (glassy) & $25-27$ & 4.16 & Point 2 - MC & A \\
\hline 16 & 1.22 & 0 & 1 & $0-0.2$ & Calm (glassy) & $25-27$ & 2.08 & Point 2 - MC & B \\
\hline 17 & 1.71 & 0 & 1 & $0-0.2$ & Calm (glassy) & $29-30$ & 4.22 & Point 2 - MC & A \\
\hline 18 & 0.49 & 0 & 0 & 0.00 & Calm (glassy) & $29-30$ & 2.6 & Point 2 - MC & B \\
\hline 19 & 7.19 & 1 & 3 & $0.5-1$ & Calm (rippled) & $20-22$ & 1.8 & Point 1 - FP & A \\
\hline 20 & 5.35 & 1 & 2 & $0.2-0.5$ & Calm (rippled) & $20-22$ & 1.72 & Point 1 - FP & B \\
\hline 21 & 7.43 & 1 & 3 & $0.5-1$ & Calm (rippled) & $25-27$ & 1.88 & Point 1 - FP & A \\
\hline 22 & 9.10 & 1 & 3 & $0.5-1$ & Calm (rippled) & $25-27$ & 2.11 & Point 1 - FP & $\mathrm{B}$ \\
\hline 23 & 7.02 & 1 & 3 & $0.5-1$ & Calm (rippled) & $29-30$ & 2.31 & Point 1 - FP & A \\
\hline 24 & 11.41 & 2 & 4 & $1-1.5$ & $\begin{array}{c}\text { Smooth } \\
\text { (wavelets) }\end{array}$ & $29-30$ & 2.23 & Point 1 - FP & B \\
\hline 25 & 8.69 & 2 & 3 & $0.5-1$ & $\begin{array}{c}\text { Smooth } \\
\text { (wavelets) }\end{array}$ & $20-22$ & 0.44 & Point 4 - MS & A \\
\hline 26 & 9.72 & 2 & 3 & $0.5-1$ & $\begin{array}{c}\text { Smooth } \\
\text { (wavelets) }\end{array}$ & $20-22$ & 1.35 & Point 4 - MS & $\mathrm{B}$ \\
\hline 27 & 9.31 & 2 & 3 & $0.5-1$ & $\begin{array}{c}\text { Smooth } \\
\text { (wavelets) }\end{array}$ & $25-27$ & 0.63 & Point 4 - MS & A \\
\hline 28 & 9.10 & 2 & 3 & $0.5-1$ & $\begin{array}{c}\text { Smooth } \\
\text { (wavelets) }\end{array}$ & $25-27$ & 1.19 & Point 4 - MS & $\mathrm{B}$ \\
\hline 29 & 5.77 & 1 & 2 & $0.2-0.5$ & Calm (rippled) & $29-30$ & 1.06 & Point 4 - MS & A \\
\hline 30 & 9.10 & 2 & 3 & $0.5-1$ & $\begin{array}{c}\text { Smooth } \\
\text { (wavelets) }\end{array}$ & $29-30$ & 1.52 & Point 4 - MS & $\mathrm{B}$ \\
\hline 31 & 6.80 & 1 & 2 & $0.2-0.5$ & Calm (rippled) & $20-22$ & 0.45 & Point 4 - MS & A \\
\hline 32 & 9.31 & 2 & 3 & $0.5-1$ & $\begin{array}{c}\text { Smooth } \\
\text { (wavelets) }\end{array}$ & $20-22$ & 1.06 & Point 4 - MS & $\mathrm{B}$ \\
\hline 33 & 7.23 & 1 & 3 & $0.5-1$ & Calm (rippled) & $25-27$ & 0.83 & Point 4 - MS & A \\
\hline 34 & 10.38 & 2 & 3 & $0.5-1$ & $\begin{array}{c}\text { Smooth } \\
\text { (wavelets) }\end{array}$ & $25-27$ & 1.32 & Point 4 - MS & B \\
\hline 35 & 7.85 & 1 & 3 & $0.5-1$ & Calm (rippled) & $29-30$ & 0.69 & Point 4 - MS & A \\
\hline 36 & 9.95 & 2 & 3 & $0.5-1$ & $\begin{array}{c}\text { Smooth } \\
\text { (wavelets) }\end{array}$ & $29-30$ & 1.41 & Point 4 - MS & B \\
\hline
\end{tabular}

Notes: FB -forward bulkhead, MC - main console area, FP - forward perpendicular, MS-midship 
Table 4 Highest deck acceleration record at aft and forward bulkhead (passenger area)

\begin{tabular}{|c|c|c|}
\hline $\begin{array}{c}\text { Craft Speed } \\
\text { (knots) }\end{array}$ & $\begin{array}{c}\text { Aft } \\
\text { Bulkhead, } \\
(\mathrm{g}) \\
\text { (Point 5) }\end{array}$ & $\begin{array}{c}\text { Fwd } \\
\text { Bulkhead, } \\
(\mathrm{g}) \\
\text { (Point 3) }\end{array}$ \\
\hline $20-22$ & 0.99 & 1.9 \\
\hline $25-27$ & 0.86 & 3.7 \\
\hline $29-30$ & 1.32 & 2.73 \\
\hline
\end{tabular}

Table 6 Highest deck acceleration record at aft bulkhead (passenger area) and main console

\begin{tabular}{|c|c|c|}
\hline $\begin{array}{c}\text { Craft Speed } \\
\text { (knots) }\end{array}$ & $\begin{array}{c}\text { Aft } \\
\text { Bulkhead, } \\
(\mathrm{g}) \\
\text { (Point 5) }\end{array}$ & $\begin{array}{c}\text { Main } \\
\text { Console, (g) } \\
\text { (Point 2) }\end{array}$ \\
\hline $20-22$ & 0.91 & 1.62 \\
\hline $25-27$ & 2.9 & 4.16 \\
\hline $29-30$ & 1.12 & 4.22 \\
\hline
\end{tabular}

\subsection{Effectiveness of ordinary foam seat}

The effectiveness of ordinary seats used on current small high speed passenger craft are assessed by the reduction in acceleration and Dynamic Response Index (DRI) as presented in Table 7 and Table 8 . Shock reduction from both tables have shown decrement in percentage as the craft experience more severe slamming impacts. Percentage of reduction of $49 \%$ can only be achieved if the slam impact is less than $0.5 \mathrm{~g}$. When the impacts are more severe, which is above $1 \mathrm{~g}$, the effectiveness of shock reduction may only achieve between $4 \%$ to $7 \%$ reduction.

Table 7 Effectiveness of ordinary foam seat - test duration of 120s per run (seat: PCB and deck: Kistler)

\begin{tabular}{|c|c|c|c|c|c|c|c|c|}
\hline $\begin{array}{c}\text { Test } \\
\text { no }\end{array}$ & Route & $\begin{array}{c}\text { Speed } \\
\text { (knots) }\end{array}$ & $\begin{array}{c}\text { Accelerometer } \\
\text { location } \\
\text { (Point 6) }\end{array}$ & $\begin{array}{c}\text { Max. } \\
\text { peak acc. } \\
\text { (deck) (g) }\end{array}$ & $\begin{array}{c}\text { Max. } \\
\text { peak acc. } \\
\text { (dummy } \\
\text { mass) (g) }\end{array}$ & $\begin{array}{c}\% \text { of } \\
\text { reduction }\end{array}$ & $\begin{array}{c}\text { Dummy } \\
\text { weight } \\
\text { disp. } \\
\text { (m) }\end{array}$ & DRI \\
\hline 25 & A & $20-22$ & Midship (port) & 0.44 & 0.35 & $20 \%$ & 0.03 & 9 \\
\hline 26 & B & $20-22$ & Midship (port) & 1.35 & 1.06 & $21 \%$ & 0.09 & 26 \\
\hline 27 & A & $25-27$ & Midship (port) & 0.63 & 0.51 & $19 \%$ & 0.04 & 13 \\
\hline 28 & B & $25-27$ & Midship (port) & 1.19 & 0.96 & $19 \%$ & 0.08 & 24 \\
\hline 29 & A & $29-30$ & Midship (port) & 1.06 & 0.96 & $9 \%$ & 0.08 & 24 \\
\hline 30 & B & $29-30$ & Midship (port) & 1.52 & 1.42 & $7 \%$ & 0.12 & 35 \\
\hline
\end{tabular}

Table 8 Effectiveness of ordinary foam seat- test duration of 120s per run (seat: Kistler and deck: PCB)

\begin{tabular}{|c|c|c|c|c|c|c|c|c|}
\hline $\begin{array}{c}\text { Test } \\
\text { no }\end{array}$ & Route & $\begin{array}{c}\text { Speed } \\
\text { (knots) }\end{array}$ & $\begin{array}{c}\text { Accelerometer } \\
\text { location } \\
\text { (Point 6) }\end{array}$ & $\begin{array}{c}\text { Max. } \\
\text { peak acc. } \\
\text { (deck) (g) }\end{array}$ & $\begin{array}{c}\text { Max. } \\
\text { peak acc. } \\
\text { (dummy } \\
\text { mass) (g) }\end{array}$ & $\begin{array}{c}\% \text { of } \\
\text { reduction }\end{array}$ & $\begin{array}{c}\text { Dummy } \\
\text { mass } \\
\text { disp. } \\
\text { (m) }\end{array}$ & DRI \\
\hline 31 & A & $20-22$ & Midship (port) & 0.45 & 0.23 & $49 \%$ & 0.02 & 6 \\
\hline 32 & B & $20-22$ & Midship (port) & 1.06 & 0.63 & $41 \%$ & 0.05 & 14 \\
\hline 33 & A & $25-27$ & Midship (port) & 0.83 & 0.56 & $33 \%$ & 0.05 & 14 \\
\hline 34 & B & $25-27$ & Midship (port) & 1.32 & 1.25 & $5 \%$ & 0.11 & 31 \\
\hline 35 & A & $29-30$ & Midship (port) & 0.69 & 0.65 & $6 \%$ & 0.06 & 17 \\
\hline 36 & B & $29-30$ & Midship (port) & 1.41 & 1.35 & $4 \%$ & 0.12 & 34 \\
\hline
\end{tabular}


These shock reduction values may show more unacceptable values if the slam impacts reach the maximum record obtained in this research at $4.22 \mathrm{~g}$, or if heavier person is seated on this ordinary foam seat. Dummy weight used in this test was only $38.4 \mathrm{~kg}$ as to represent 72.3 $\%$ of an upper body mass of a seated person to simulate a typical condition for a passenger seated on the deck seat with both feet resting on the deck [21][22]. The results also show that DRI values keep increasing with increasing slam impact. The higher the DRI values, the less effective is the seat foam in reducing the slamming impact acceleration experienced by the passengers. Both Table 7 and 8 have shown higher DRI values above the limit of 18 which corresponds to a $5 \%$ probability of spinal injury rates when the impact is more than $1 \mathrm{~g}$ experienced by passengers. This has shown good correlation with regard to the limit of $1 \mathrm{~g}$ set by International Code of Safety for High-Speed Craft (2000).

\section{Conclusion}

This research work was conducted to assess slamming impacts experienced by small high speed passenger craft which are mainly used to transport tourists between popular island destinations in Malaysia. The results obtained from the full-scale slamming test shows that the slamming impact for these types of crafts have the potential to cause injury to passengers onboard where the maximum slam impact may reach $4.22 \mathrm{~g}$ and the average impact is $2.20 \mathrm{~g}$. These acceleration values are far beyond safe level of $1 \mathrm{~g}$ set by International Code of Safety for High-Speed Craft (2000) [5]. The ordinary seat foam used on certain craft are also not effective enough in reducing the slam impact towards passengers as only $4 \%$ to $7 \%$ shock reduction can be achieved above $1 \mathrm{~g}$ slam impact. The safety limit criteria for DRI value of 18 were not achieved for this ordinary seat foam, hence may expose passenger to probability of spinal fracture. The results obtained from this research have indicated the need to reduce slamming impacts experienced by passengers by introducing a shock absorbing seat mechanism which can absorb the impacts more efficiently. Also, it can be deduced from the results that the operating speed of this type of craft should not reach beyond 25 knots in speed unless the current seat is equipped with effective shock absorbing seat which is capable to reduce the impacts by more than $50 \%$.

\section{ACKNOWLEDGEMENTS}

This research is supported by Ministry of Higher Education (MOHE), Malaysia under its Fundamental Research Grant Scheme (FRGS) number FRGS/1/2017/TK08/UTM/01/1.

\section{REFERENCES}

[1] D. J. Taunton, D. A. Hudson, and R. A. Shenoi, "Characteristics of a series of high speed hard chine planing hulls - part II: Performance in waves," Trans. R. Inst. Nav. Archit. Part B Int. J. Small Cr. Technol., vol. 153, no. 1, 2011.

[2] M. Razola, K. Olausson, K. Garme, and A. Rosén, "On high-speed craft acceleration statistics," Ocean Eng., vol. 114, pp. 115-133, 2016. https://doi.org/10.1016/j.oceaneng.2016.01.004

[3] K. Rawson and E. C. Tupper, Basic Ship Theory, 5th Editio., vol. 2. Oxford: Butterworth Heinemann, 2001. 
[4] N. Santoro, E. Begovic, C. Bertorello, A. Bove, S. De Rosa, and F. Franco, "Experimental study of the hydrodynamic loads on high speed planing craft," in Procedia Engineering, 2014, vol. 88, pp. 186-193. https://doi.org/10.1016/j.proeng.2014.11.143

[5] MCA, International Code of Safety for High Speed Craft (2000). 2008.

[6] Y. Fouad, "An experimental methodology for characterizing high speed craft seat suspension components," Master Thesis, Carleton University Ottawa, 2014.

[7] D. Jamison, M. Cannella, E. C. Pierce, and M. S. Marcolongo, "A comparison of the human lumbar intervertebral disc mechanical response to normal and impact loading conditions.," J. Biomech. Eng., vol. 135, no. September, pp. 1-5, 2013. https://doi.org/10.1115/1.4024828

[8] N. Kalkan, "Human Factors and Ergonomic Considerations for Super Fast Boat Design," Environ. Sci., vol. 10, no. 9, pp. 3483-3507, 2013.

[9] MAIB, "Delta 8.5m RIB Report No 1/2011, Marine Accident Investigation Branch, Southampton, United Kingdom,” 2011.

[10] M. Razola, "On Structural Design of High-Speed Craft," PhD Thesis, KTH School of Engineering Sciences, 2013.

[11] E. V. Lewis, Principal of Naval Architecture, Stability and Strength, 2nd revisi., vol. I. Jersey City, NJ: SNAME, 1988.

[12] M. R. Riley, T. Coats, K. Haupt, and D. Jacobson, "Ride severity index: a simplified approach for comparing peak acceleration responses of high-speed craft," J. Sh. Prod. Des., vol. 29, no. 1, pp. 25-35, 2013. https://doi.org/10.5957/JSPD.29.1.120051

[13] M. R. Riley, T. W. Coats, and H. Murphy, “Acceleration response mode decomposition for quantifying wave impact load in high speed planing craft," Virginia Beach, Virginia, 2014. https://doi.org/10.21236/ADA621230

[14] P. De Alwis, "Methods for Shock and Vibration Evaluation Applied on Offshore Power Boats," Master Thesis, KTH Royal Institute of Technology, Stockholm, Sweden, 2014.

[15] A. Wice, "Spatial dynamic modelling of high speed craft suspension seating," Master Thesis, Carleton University Ottawa, 2015.

[16] J. C. Kirstein, "Suspension system optimisation of an articulated dump truck to reduce whole body vibration," Master Thesis, Department of Mechanical Engineering Stellenbosch University, 2005.

[17] D. Reynolds, E. A. Ayyad, and M. Hachem, "Evaluation of a pneumatic-seat-bladder-system designed for shock and vibration isolation," 2012.

[18] “U.S. Air Force. (1967).," Sent Syst. Upward Ejection, Aircraft, Gen. Specif. for, MIL-S-9479B. USAF., 1967.

[19] L. A. Destefano, "Dynamic Response Index Minimization for Personnel Escape Systems," Natl. Tech. Inf. Serv. U.S Dep. Commer., 1972.

[20] C. Liam, "Testing and Modeling of Shock Mitigating Seats for High Speed Craft," Master Thesis, Virginia Polytechnic Institute and State University, 2011.

[21] K. Olausson and K. Garme, "Prediction and Evaluation of Working Conditions on High-Speed Craft Using Suspension Seat Modelling," Proc. Inst. Mech. Eng. Part M-Journal Eng. Marit. Environ., vol. 229, no. 3, pp. 281-290, 2015. https://doi.org/10.1177/1475090213515641

[22] T. E. Fairley and M. J. Griffin, "The apparent mass of the seated human body: Vertical vibration," $J$. Biomech., vol. 22, no. 2, pp. 81-94, 1989. https://doi.org/10.1016/0021-9290(89)90031-6

[23] E. Begovic et al., "Experimental modelling of local structure responses for high-speed planing craft in waves," Ocean Eng., vol. 216, no. May, pp. 1-13, 2020. https://doi.org/10.1016/j.oceaneng.2020.107986

[24] E. Begovic, C. Bertorello, S. Pennino, V. Piscopo, and A. Scamardella, "Statistical analysis of planing hull motions and accelerations in irregular head sea," Ocean Eng., vol. 112, pp. 253-264, 2016. https://doi.org/10.1016/j.oceaneng.2015.12.012

[25] A. Rosén, E. Begovic, M. Razola, and K. Garme, "High-speed craft dynamics in waves : challenges and opportunities related to the current safety philosophy," in Proceedings of the 16th International Ship Stability Workshop, 5-7 June 2017, Belgrade, Serbia, 2017, no. June, pp. 1-10.

[26] J. Camilleri, D. J. Taunton, and P. Temarel, "Full-scale measurements of slamming loads and responses on high-speed planing craft in waves," J. Fluids Struct., vol. 81, pp. 201-229, 2018. https://doi.org/10.1016/j.jfluidstructs.2018.05.006

[27] M. R. Riley, K. D. Haupt, and H. P. Murphy, “An Investigation of Wave Impact Duration in High-Speed 
Planing Craft in Rough Water," Virginia Beach, Virginia, 2014.

[28] O. M. Faltinsen, Hydrodynamics of High Speed Marine Vehicles. New York, USA: Cambridge University Press, 2005. https://doi.org/10.1017/CBO9780511546068

\footnotetext{
Submitted: $\quad$ 09.04.2020 $\quad$ Faisal Ikram Bin Abd Samad ${ }^{\text {b,c }}$, (Snr Lecturer, Ph.D. student) faisalikram@unikl.edu.my

Accepted: $\quad$ 15.03.2021. Omar Bin Yakob ${ }^{\mathrm{a}, \mathrm{b}}$, (Professor, Ph.D) omaryakob@utm.my Nik Mohd Ridzuan Bin Shaharuddin ${ }^{\mathrm{a}, \mathrm{b}}$, (Senior Lecturer, Ph.D.) ridzuan@mail.fkm.utm.my (corresponding) Mohd Yuzri Bin Mohd Yusop ${ }^{c}$, ( Assoc. Professor Ph.D.,) Nasrudin Bin Ismail a,b, (Snr Lecturer)

${ }^{a}$ Marine Technology Center, Universiti Teknologi Malaysia, 81310 UTM Skudai, Johor Darul Takzim, Malaysia

${ }^{\mathrm{b}}$ School of Mechanical Engineering, Faculty of Engineering, Universiti Teknologi Malaysia, 81310 UTM Skudai, Johor Darul Takzim, Malaysia ${ }^{\mathrm{c}}$ Malaysian Institute of Marine Engineering Technology, Universiti Kuala Lumpur, 32200 Lumut, Perak, Malaysia
} 